\title{
Antioxidant and antiproliferative activity of blue corn and tortilla from native maize
}

\author{
Mónica Y. Herrera-Sotero ${ }^{1}$, Carlos D. Cruz-Hernández², Carolina Trujillo-Carretero3, \\ Mauricio Rodríguez-Dorantes², Hugo S. García-Galindo', José L. Chávez-Servia ${ }^{4}$, Rosa M. Oliart-Ros ${ }^{1}$ \\ and Rosa I. Guzmán-Gerónimo $3^{3^{*}}$
}

\begin{abstract}
Background: Blue corn is a cereal rich in phenolic compounds used to make blue tortillas. Tortillas are an important part of the Mexican diet. Blue corn and tortilla represent an important source of the natural antioxidants anthocyanins. However, studies on their biological activity on cancer cell lines are limited. The goal of this study was to evaluate the antioxidant and antiproliferative activity of blue corn and tortilla on different cancer cell lines.

Methods: Total polyphenol content, monomeric anthocyanins, and antioxidant activity by the DPPH and TBARS methods of blue corn and tortilla were determined. The anthocyanin profile of tortilla was obtained by means of HPLC-ESI-MS. The antiproliferative activity of blue corn and tortilla extract on HepG2, H-460, Hela, MCF-7 and PC-3 was evaluated by the MTT assay.

Results: Blue corn had higher content of total polyphenols and monomeric anthocyanins as well as lower percentage of polymeric color than tortilla; however, both showed similar antioxidant activity by DPPH. In addition, although a higher degradation of anthocyanins was observed on tortilla extract, both extracts inhibited lipid peroxidation (IC50) at a similar concentration. The anthocyanin profile showed 28 compounds which are primarily derived from cyanidin, including acylated anthocyanins and proanthocyanidins. Blue corn and tortilla extracts showed antiproliferative effects against HepG2, H-460, MCF-7 and PC-3 cells at 1000 mg/mL, however Hela cells were more sensitive at this concentration.

Conclusion: This is the first report to demonstrate anticancer properties in vitro of tortilla derived from blue corn, suggesting that this product has beneficial health effects. In addition, blue corn could be a potential source of nutraceuticals with anticancer activity.
\end{abstract}

Keywords: Blue corn, Tortilla, Antioxidant, Antiproliferative, Anthocyanins

\section{Background}

Epidemiological studies from several countries point out that consumption of fruits, vegetables and cereals reduce the risk of chronic degenerative diseases due to the presence of bioactive compounds such as phenolic compounds $[1,2]$. In recent years, pigmented cereals such as red, purple and black rice, black sorghum, and blue

\footnotetext{
${ }^{*}$ Correspondence: roguzman@uv.mx

${ }^{3}$ Instituto de Ciencias Básicas, Universidad Veracruzana, Av. Dr. Luis Castelazo Ayala s/n Col. Industrial Ánimas, 91190 Xalapa, Veracruz, Mexico Full list of author information is available at the end of the article
}

or purple maize have been the focus of scientific studies since they are a potential source of anthocyanins [3].

Mexico is the center of origin and biodiversity of maize (Zea mays L.). Species have an extensive genetic diversity, with 59 different races described with different shapes and colors ranging from white to yellow, red, purple and blue [4]. Maize (Zea mays L.) is the most important cereal in Mexico from which tortilla is produced. Tortillas are a staple food for Mexicans, consumed by $94 \%$ of the Mexican population, with a $335 \mathrm{~g} /$ day consumption per capita, equivalent to $122 \mathrm{~kg} /$ year [5].

In recent years, tortillas produced from blue maize have been the focus of scientific studies due to their 
anthocyanin content $[6,7]$. From the chemical standpoint, anthocyanins are phenolic substances that belong to the group of flavonoids derived from the 2-phenylbenzopyrilic cation that is found in nature in a glycosylated or acylated form [2]. Several studies indicate that anthocyanins have antioxidant and anticancer properties [8, 9]. However, their biological properties are affected by food processing conditions. Nixtamalization, also known as alkaline cooking, is the traditional process for making corn dough used to prepare tortillas. From the nutritional point of view, nixtamalization has several benefits: increases calcium content, makes niacin available and reduces the amount of mycotoxins present in maize [10].

On the other hand, nixtamalization causes degradation of anthocyanins. Several studies on the effect of nixtamalization on blue tortilla have been focused on the changes of total content, profile, and antioxidant activity of anthocyanins [11, 12]. However, the number of studies related to the anticancer activity of blue corn and tortilla is limited. Given the above, the aim of this study was to determine the antioxidant properties and antiproliferative activities of blue corn and tortilla from native maize on liver, lung, cervix, breast and prostate cancer cell lines.

\section{Experimental}

\section{Plant material and chemicals}

Blue corn from the Mixteco maize variety was collected in the Mixteca region of Oaxaca, Mexico during 2012. For the chemical and biological analysis, sodium acetate, anhydrous sodium carbonate, potassium chloride, dimethyl sulfoxide (DMSO), folin reagent, gallic acid, ethanol, potassium acetate, quercetin, iron(III) chloride, hydrochloric acid, trolox, 2,2-difenil-1-picril-hidrazil (DPPH), amberlite XAD-7, acetic acid, 3-(4,5-dimethylthiazol-2-yl)-2,5-diphenyltetrazolium bromide (MTT) were obtained from Sigma-Aldrich. Trypsin, fetal bovine serum (FBS), GlutaMAX $(100 \times)$ were purchased from Gibco. Dulbecco's Modified Eagle's medium (DMEM), Roswell Park Memorial Institute Medium (RPMI-1640) and phosphate buffer saline (PBS) tablet were supplied by Lonza.

\section{Tortilla preparation}

Traditional nixtamalization was done by boiling blue corn in a solution of $1 \%$ calcium hydroxide at $92^{\circ} \mathrm{C}$ for $35 \mathrm{~min}$. After standing for $16 \mathrm{~h}$, the cooked blue corn nixtamal was rinsed three times with $1 \mathrm{~L}$ of purified water. Then it was grounded in a manual grinder to obtain dough. A domestic press was used to make tortillas with a thickness of $1 \pm 0.5 \mathrm{~mm}, 12 \pm 0.5 \mathrm{~cm}$ in diameter and $17.5 \pm 0.5 \mathrm{~g}$ in weight. Discs of dough were put into a pan at $240 \pm 2{ }^{\circ} \mathrm{C}$ for $30 \mathrm{~s}$ on the side $\mathrm{A}$, followed by $65 \mathrm{~s}$ on side $\mathrm{B}$, and $30 \mathrm{~s}$ again on the side $\mathrm{A}$.

\section{Blue corn and tortilla extracts}

Ground blue corn or tortilla (1:5 p:v) were homogenized with ethanol acidified with citric acid $1 \mathrm{M}$. This was performed using an ultrasonic homogenizer $(20 \mathrm{kHz}, 750 \mathrm{~W}$, Cole-Palmer Instrument Company, VCX-750, USA). The sample was placed under refrigeration for $24 \mathrm{~h}$ and centrifuged at $4000 \mathrm{rpm}$ for $15 \mathrm{~min}$ at a temperature of $5^{\circ} \mathrm{C}$. The process was repeated twice and the extract was concentrated using a rotary evaporator under vacuum. Extensive extractions were performed in order to obtain the highest content of polyphenols and anthocyanins. The conditions of extraction have been included in a patent request, MX/A/20131011202.

\section{Total phenolic content}

The Folin-Ciocalteau method modified by Singleton and Rossi [13], was used to evaluate the total polyphenol content. The absorbance was measured at $750 \mathrm{~nm}$. The total phenolic content was expressed as milligram equivalents of gallic acid/100 $\mathrm{g}$ of fresh weight (mg GAE/100 $\mathrm{g} \mathrm{FW).}$

\section{Total anthocyanin content}

Monomeric anthocyanins were quantified using the $\mathrm{pH}$ differential method previously described by Giusti and Wrolstad [14]. Samples were diluted with $0.025 \mathrm{M}$ potassium chloride buffer solutions at $\mathrm{pH} 1$ and $0.4 \mathrm{M}$ sodium acetate buffer at $\mathrm{pH} 4.5$. A 400-700 nm sweep was done by using a spectrophotometer (PerkinElmer model Lambda 25 UV/VIS, USA). The monomeric anthocyanins content was expressed as mg of cyanidin-3-glucoside (C3G) per $100 \mathrm{~g}$ sample based on a molar extinction coefficient of $26,900 \mathrm{~L} \mathrm{~cm}^{-1} \mathrm{mg}^{-1}$ and a molecular weight of $449.2 \mathrm{~g} / \mathrm{L}$.

\section{Antioxidant activity by DPPH}

Antioxidant activity was determined by the DPPH method [15]. A standard calibration curve was established using trolox as the standard $(100-800 \mu \mathrm{M})$. The radical DPPH $(2.9 \mathrm{~mL})$ was added to $0.1 \mathrm{~mL}$ of each extract. The mixture was incubated for $30 \mathrm{~min}$ in total darkness and the absorbance was read at $517 \mathrm{~nm}$. The results were expressed in $\mu \mathrm{mol}$ equivalents of trolox $\mathrm{g}^{-1}$ of the sample (ET).

\section{TBARS assay}

The evaluation of lipid peroxidation was performed by the TBARS method following the methodology described by Ohkawa [16]. For this, $400 \mu \mathrm{L}$ of homogenized rat brain were mixed with $50 \mu \mathrm{L}$ of extracts $(500-1000 \mu \mathrm{g} /$ $\mathrm{mL}$ ) and incubated for $30 \mathrm{~min}$ at $37{ }^{\circ} \mathrm{C}$. Lipid peroxidation with $50 \mu \mathrm{L}$ of FeSO4 $100 \mu \mathrm{M}$ was induced, and after $1 \mathrm{~h}$ at $37^{\circ} \mathrm{C}, 500 \mu \mathrm{L}$ of TBA reagent was added and the absorbance at $540 \mathrm{~nm}$ was measured. 


\section{Isolation and chromatography analysis}

A $45 \times 1.5 \mathrm{~cm}$ column was packed with amberlite XAD-7 pre-conditioned with acidified water (5\% acetic acid) [17]. The resin was washed with $200 \mathrm{ml}$ of acidified water (5\% acetic acid) and $1 \mathrm{~mL}$ of the blue corn or tortilla crude extract was added placed and washed with $100 \mathrm{~mL}$ of acidified water; the polymer mixture was eluted with $200 \mathrm{~mL}$ of acidified ethanol (5\% acetic acid). The eluate was concentrated in a rotary evaporator (Heidolph Digital Laborota pump 4011 coupled to V Pimo Vacum Buchi 700) at $28{ }^{\circ} \mathrm{C}$ and stored at $4{ }^{\circ} \mathrm{C}$ until use. Separation of the compounds was performed using an HPLC equipped with a C-18 ZORBAX eclipse plus column $(100 \mathrm{~mm} \times 2.1 \mathrm{~mm}, 3.5 \mu \mathrm{m})$ under isocratic elution with methanol: water $(2: 8 \mathrm{v}: \mathrm{v})$. The HPLC system was coupled to a Brüker MicrOTOF II spectrometer operating in negative ion mode, scan range: 50-3000 amu, capillary voltage $3.8 \mathrm{kV}$, dry gas flow at $4.0 \mathrm{~L} \mathrm{~min}^{-1}$ and heated capillary temperature of $180{ }^{\circ} \mathrm{C}$. Under these conditions an electrospray ionization-mass spectrometry (ESI-MS) analysis of the isolated compounds was performed.

\section{MTT assay}

Hepatocellular carcinoma (HepG2), lung carcinoma (H-460), cervix adenocarcinoma (Hela), breast adenocarcinoma (MCF-7), and androgen-independent prostate adenocarcinoma (PC-3) human cancer cell lines were obtained from the American Type Culture Collection, United States of America (ATCC, U.S). PC-3 cells were maintained in RPMI-1640 medium which contained $10 \%$ FBS, $1 \%$ L-glutamine and $0.1 \%$ piruvate. HepG2, Hela, H460 and MCF-7 cells were maintained in DMEM medium which contained $10 \%$ FBS. The antiproliferative action of ethanolic extracts of tortilla and blue maize of the Mixteco variety was evaluated in HepG2, H460, Hela, MCF-7 and PC-3 cancer cell lines. For this, cells in 96 -well plates were grown to $80 \%$ confluency. The cell count was performed using a Neubauer chamber, 5000 cells were seeded per well for PC-3 and 10,000 cells per well for HepG2, H-460, Hela and MCF-7. The blue corn and tortilla extracts were applied in concentrations of $125,250,500$ and $1000 \mu \mathrm{g} / \mathrm{mL}, 100 \mu \mathrm{L}$ per well. Cell culture in medium was used as a negative control, R (-), and quercetin $50 \mu \mathrm{M}$ as a positive control, $\mathrm{R}(+)$. Extracts and quercetin were solubilized in culture medium. Treatments were allowed to incubate for $48 \mathrm{~h}$. Post incubation time cells were treated with $5 \mathrm{mg} / \mathrm{mL}$ of MTT $(10 \mu \mathrm{L}$ per well) and incubated at $37{ }^{\circ} \mathrm{C}, 5 \% \mathrm{CO}_{2}$ for $2 \mathrm{~h}$. Finally, $100 \mu \mathrm{L}$ of DMSO were added, the absorbance was determined at $595 \mathrm{~nm}[18]$.

\section{Statistical analysis}

Data analysis was performed using the GraphPad Prism 6.0 statistics software. Analysis of variance (ANOVA) and Tukey's test comparison with a $95 \%$ confidence interval were performed. The results of cell viability are presented as mean $\pm \mathrm{SD}$ of independent experiments.

\section{Results and discussion}

Total content polyphenols, monomeric anthocyanins, percent polymeric color and antioxidant activity in blue corn and tortilla

In the present study, the content of total polyphenols, monomeric anthocyanins and percent polymeric color in the grain of blue corn and the tortilla derived from it were evaluated, since it is relevant to know how the tortilla preparation process affects the concentration of phenolic compounds such as anthocyanins. The total phenolics value for blue corn was of 287.3, and $70.3 \mathrm{mg}$ GAE/100 g for tortilla; while the monomeric anthocyanins content was 70.50 and $27.8 \mathrm{mg}$ C3G/100 g in blue corn and tortilla, respectively (Table 1). According to literature data, a decrease in the concentration of polyphenols and anthocyanins in tortilla could be attributed to the nixtamalization process, were high temperature and alkaline conditions are applied [11, 12]. It has been estimated that $40-80 \%$ of anthocyanins may be lost during the transformation of blue corn grain to tortilla [19]. However, research made on blue corn tortilla show that the remaining amount of anthocyanins is enough to maintain antioxidant properties [11].

In addition, higher percent polymeric color values were observed for tortilla as compared to blue corn, which suggests the formation of polymers during the process. A study done by Lao and Giusti [20] suggests that percent polymeric color can be used as indicator of the effect of

Table 1 Total polyphenol content, monomeric anthocyanins and antioxidant activity by DPPH and TBARS methods of blue corn and tortilla

\begin{tabular}{|c|c|c|c|c|c|}
\hline Sample $^{1}$ & $\begin{array}{l}\text { Total polyphenols } \\
\text { (mg EAG/100 g) }\end{array}$ & $\begin{array}{l}\text { Monomeric anthocyanins } \\
\text { (mg C3G/100 g) }\end{array}$ & $\begin{array}{l}\text { Percent } \\
\text { polymeric color }\end{array}$ & $\begin{array}{l}\text { DPPH } \\
(\mu \mathrm{M} \mathrm{ET} / \mathrm{g})\end{array}$ & $\begin{array}{l}\text { TBARS IC50 } \\
\text { value }(\mu \mathrm{g} / \mathrm{mL})\end{array}$ \\
\hline Blue corn & $287.3 \pm 0.03^{a}$ & $70.50 \pm 1.3^{\mathrm{a}}$ & $54.0 \pm 2.06^{\mathrm{a}}$ & $49.2 \pm 0.18^{a}$ & $792 \pm 64.4^{a}$ \\
\hline Blue tortilla & $70.3 \pm 0.03^{b}$ & $27.8 \pm 1.8^{b}$ & $66.1 \pm 0.31^{b}$ & $45.1 \pm 0.22^{a}$ & $750 \pm 5.61^{a}$ \\
\hline
\end{tabular}

GAE gallic acid equivalentes, ET trolox equivalente, C3G cyanidin 3-glucoside

1 The results are expressed as mean \pm SD. Different letters indicate that there are significant differences $(p \leq 0.05)$ 
corn processing in anthocyanins. On the other hand, previous studies in thermally processed foods suggest that an increase in anthocyanin polymers has a positive effect on antioxidant activity [21].

On this regard, we used the DPPH and TBARS assays to provide information on the antioxidant activity of blue corn and tortilla extracts. The radical-scavenging activity by DPPH of these extracts is shown in Table 1. Interestingly, although tortilla extract showed a decrease on phenolics, it had slightly lower values of DPPH $(45.1 \mu \mathrm{M}$ $\mathrm{ET} / \mathrm{g}$ FW) than blue corn $(49.2 \mu \mathrm{M}$ ET/g FW). Similar data were obtained by the TBARS assay (Table 1). The concentration of blue corn extract required to inhibit TBARS production by $50 \%$ (IC50) was slightly lower $(750 \mu \mathrm{g} / \mathrm{mL})$ than the one recorded for tortilla extract $(792 \mu \mathrm{g} / \mathrm{mL})$. These results suggest that changes in phenolic compounds such as anthocyanins on blue corn due to the nixtamalization process may improve its biological properties.

\section{HPLC-ESI-MS}

The anthocyanin composition of blue tortilla (Fig. 1) was estimated by HPLC coupled to mass spectrometry. A total of 28 compounds derived from cyanidin were tentatively identified in the blue tortilla extract (Table 2), including cyanidin-3-glucoside, four acylated anthocyanins and fifteen proanthocyanidins. It has been reported that during the process of nixtamalization, an alkaline hydrolysis takes place liberating the acid part of acylated anthocyanins, resulting in monoglycosylated forms of anthocyanins such as cyanidin-3-glucoside [19]. Previous studies point out that anthocyanins in blue maize grain are mainly acylated, which are more stable to alkaline $\mathrm{pH}$ and high temperatures [7, 22].

The data obtained by percent polymeric color reveal that polymerized compounds are present in blue tortilla (Table 2). Studies on chemical composition on blue tortilla from different maize varieties mainly report monomeric and acylated anthocyanins [19], while the presence of proanthocyanidins had not been observed. In this study, the number of anthocyanins detected and discrepancies in their profile with previous reports could be attributed to the maize variety, as well as to the nixtamal process, where anthocyainins may be degraded or react among themselves, or even polymerize at the given alkaline and temperature conditions. The extraction method may also have an impact on anthocyanin profile. For better anthocyanin extraction, previous reports recommend to use weak organic acids and low concentrations of strong acids such as hydrochloric acid (<1.0\%) [23]. A study done by Lao and Giusti [20] report that high concentration hydrochloric acid could break the glycosidic bond of monomeric anthocyanins and hydrolyze polymeric pigments into smaller molecules. For this reason, we used ethanol acidified with citric acid since organic acids decrease the decomposition of anthocyanins during the concentration of extracts [24, 25]. Furthermore, it has been reported that acidic conditions allow a higher extraction of proanthocyanidins by preventing autoxidation and decreasing their polar interactions with the cell wall [26]. On this regard, our research team has studied different samples of blue tortilla made from other maize varieties, where proanthocyanidins have also been detected (unpublished data). As far as we know, this is a first report of proanthocyanidins on blue tortilla.

It is important to say that although the tortilla showed a decrease in the content of anthocyanins as compared to the grain (Table 1), the chemical changes due to the tortilla preparation process may be beneficial from the biological activity standpoint, as suggested by the antioxidant activity assays that were made in the present study. It could be attributed to the chemical composition of anthocyanin profile of tortilla where the presence of monomeric anthocyanins and proanthocyanidins were detected.

\section{Antiproliferative activity}

In order to shed light on anticancer properties of blue corn and tortilla extracts, we investigated their antiproliferative activity on different cancer cell lines:

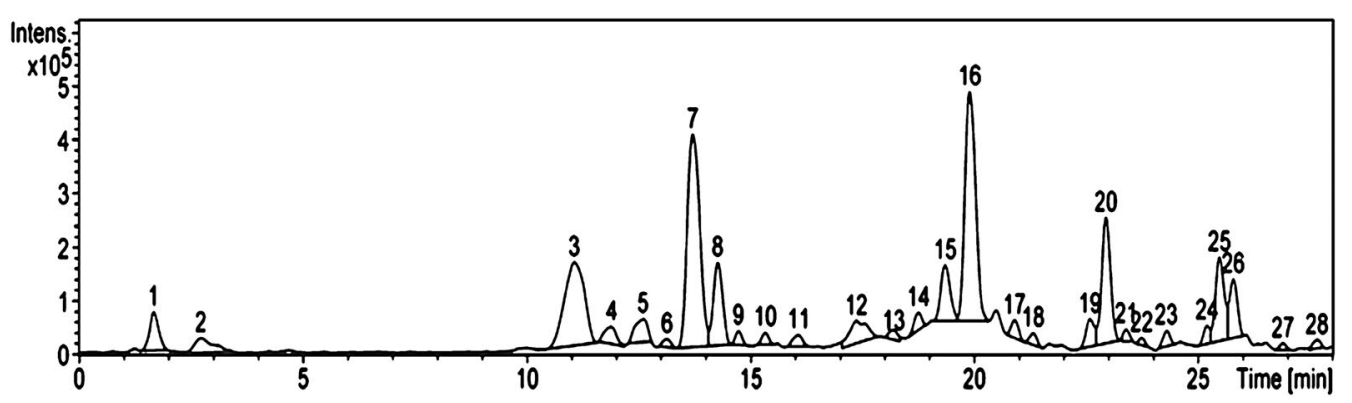

Fig. 1 Anthocyanin profile of blue tortilla obtained by means of HPLC-ESI-MS 
Table 2 Identification of anthocyanins in tortilla extract from blue Mixteco maize

\begin{tabular}{|c|c|c|c|c|}
\hline Peak & RT (min) & {$[\mathrm{M}]^{+}(\mathrm{m} / \mathrm{z})$} & Fragments ions (m/z) & Compound \\
\hline 1 & 1.7 & 611 & 449,287 & Cyanidin-3,5-diglucoside \\
\hline 2 & 2.7 & 449 & 287 & Cyanidin-3-glucoside \\
\hline 3 & 11.1 & 493 & 287 & Unidentified \\
\hline 4 & 11.9 & 563 & 287 & Cyanidin-3-(6-ethylmalonylglucoside) \\
\hline 5 & 12.6 & 565 & 287 & Cyanidin-3-(malonyl)glucoside \\
\hline 6 & 13.1 & 735 & 460,287 & Unidentified \\
\hline 7 & 13.7 & 737 & 460,292 & Unidentified \\
\hline 8 & 14.3 & 490 & 287,162 & Cyanidin-3-O-(6"-acetyl-galactoside) \\
\hline 9 & 14.7 & 520 & 287,162 & Cyanidin-3-O-(6"-piruvoyl-glucoside) \\
\hline 10 & 15.3 & 725 & 287,162 & Unidentified \\
\hline 11 & 16.1 & 615 & $510,287,162$ & Unidentified \\
\hline 12 & 17.4 & 789 & $589,303,152$ & Proanthocyanidin dimer \\
\hline 13 & 18.2 & 877 & $717,597,347$ & Unidentified \\
\hline 14 & 18.7 & 921 & $641,471,403,303,162$ & Proanthocyanidin dimer \\
\hline 15 & 19.3 & 843 & $685,433,287,162$ & Proanthocyanidin dimer \\
\hline 16 & 19.9 & 903 & 729,463 & Unidentified \\
\hline 17 & 20.9 & 817 & $757,617,463,287,162$ & Proanthocyanidin tetramer \\
\hline 18 & 21.3 & 861 & $801,669,477,287,162$ & Proanthocyanidin trimer \\
\hline 19 & 22.6 & 871 & $801,671,606,538,425,287,162$ & Proanthocyanidin trimer \\
\hline 20 & 22.9 & 901 & $636,538,287,176$ & Proanthocyanidin trimer \\
\hline 21 & 23.4 & 901 & $801,666,463,375,287,176$ & Proanthocyanidin trimer \\
\hline 22 & 23.7 & 901 & $801,655,463,287,162$ & Proanthocyanidin trimer \\
\hline 23 & 24.3 & 843 & $637,502,417,337,162$ & Proanthocyanidin trimer \\
\hline 24 & 25.2 & 871 & $637,467,287,176$ & Proanthocyanidin trimer \\
\hline 25 & 25.5 & 901 & $729,597,463,325,176$ & Proanthocyanidin trimer \\
\hline 26 & 25.8 & 901 & $843,627,463,287,176$ & Proanthocyanidin trimer \\
\hline 27 & 26.9 & 901 & $729,635,439,299,177$ & Proanthocyanidin trimer \\
\hline 28 & 27.6 & 885 & $725,339,154$ & Proanthocyanidin trimer \\
\hline
\end{tabular}

hepatocellular carcinoma (HepG2), lung carcinoma (H-460), cervix adenocarcinoma (Hela), mammary adenocarcinoma (MCF-7) and prostate cancer androgen dependent (PC-3) as shown in Figs. 2, 3. These cell lines were selected because they represent the types of cancer with the highest incidence and mortality in Mexico [27].

For HepG2, H-460, MCF-7and PC-3 cancer cell lines, the blue corn extract significantly inhibited cell proliferation at $1000 \mu \mathrm{g} / \mathrm{mL}$, (Figs. 2, 3). Interestingly, tortilla extract inhibited cell growth of these cancer lines at a lower concentration $(250$ and $500 \mu \mathrm{g} / \mathrm{mL}$ ). However, blue corn as well as tortilla extracts exhibited the highest antiproliferative activity against HepG2, H-460, MCF-7 and PC-3 at $1000 \mu \mathrm{g} / \mathrm{mL}$. It can be also observed that for these cell lines both extracts showed similar antiproliferative activity at this concentration, suggesting that the tortilla process is beneficial. These results are consistent with the findings by TBARS assay (Table 1 ), where the blue corn and tortilla extracts decreased lipid peroxidation (IC50) at similar concentrations. These data are clearly interesting, since they imply that processing of blue corn into tortilla increases health benefits. Previously, other studies reported anthocyanin content, antioxidant activity and the profiles of these compounds for blue corn and tortilla; however, specialized research on anticancer properties of blue corn and tortilla are scarce.

On the other hand, among all the cancer cell lines tested, blue corn and tortilla extract showed the highest antiproliferative activity in Hela. It is noteworthy that tortilla extract $(61.04 \pm 1.9 \%)$ showed slightly lower cell viability than blue corn extract $(68.69 \pm 2.6 \%)$ for the concentration of $1000 \mu \mathrm{g} / \mathrm{mL}$. It could be attributed to changes on anthocyanin profile during nixtamalization, which probably favors the antiproliferative activity of tortilla extract in the cell line Hela. This evidence highlights once again the importance of the traditional nixtamalization process to make tortilla, particularly its effect on anthocyanins, compounds with anticancer properties. 

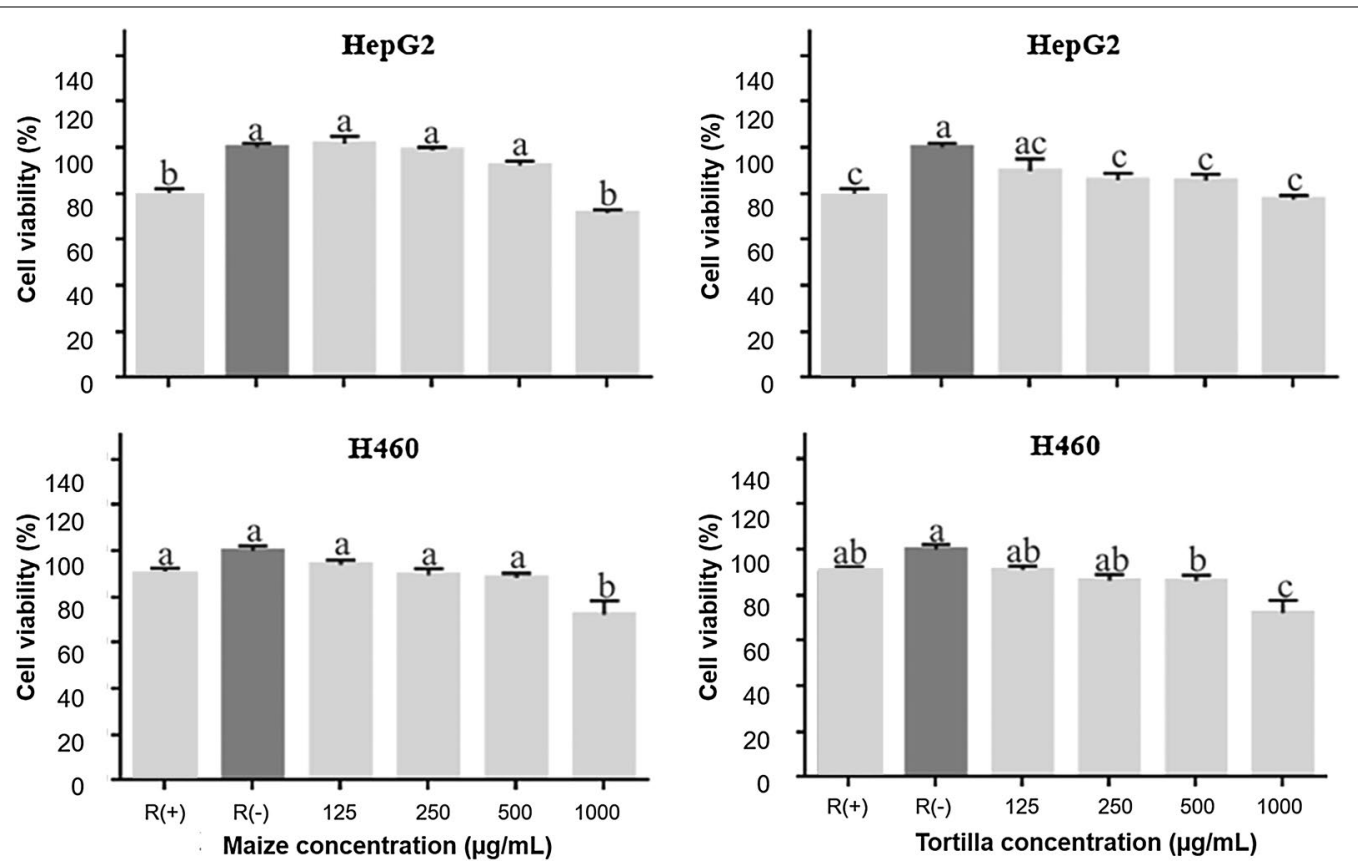

Fig. 2 Effect of blue corn and tortilla extracts on cell viability in HepG2 and H460 human cancer cell lines. R (+). Quercetin $50 \mu$. R (-). Culture medium. Different letters indicate that there are significant differences $(p \leq 0.05)$

A study done by Bagchi et al. [28] found that grape seed proanthocyanidins offered more protection against free radical-induced lipid peroxidation compared to vitamin $C, E$ and $\beta$-carotene. Also, research into the effect of strawberry extract enriched with ellagitannins and proanthocyanidins indicate that it was most cytotoxic against tumourigenic clones and lymphocytes [29].

The proanthocyanidins are phenolic compounds that have shown chemoprotective properties against oxygen free radicals and oxidative stress; however, the mechanisms behind their anti-cancer activity have not been completely elucidated. Some authors suggest that the complexity of proanthocyanidins allows them to interfere in signaling systems [30].

Nevertheless, several molecules present in foods, such as quercetin, can inhibit the growth of cancer cells [31]. Therefore, we compared the antiproliferative activity of blue corn and tortilla extracts against quercetin $50 \mu \mathrm{M}$ in all studied cell lines. Our results provide evidence that blue corn and tortilla extracts have similar antiproliferative activity in HepG2, MCF-7 and PC-3 or even better results in Hela and $\mathrm{H}-460$ cell lines than the ones given by quercetin $50 \mu \mathrm{M}$. These results are promising and provide new information on anticancer properties of nixtamalization products, specifically tortilla prepared from blue corn.

\section{Conclusion}

Our study is the first report showing that traditional tortilla-making process from blue corn favors antiproliferative activity in several cancer cell lines. This evidence highlights the importance of the traditional nixtamalization process, particularly its effect on anthocyanins. The findings suggest that consumption of blue corn and tortilla could have a positive effect on health. 

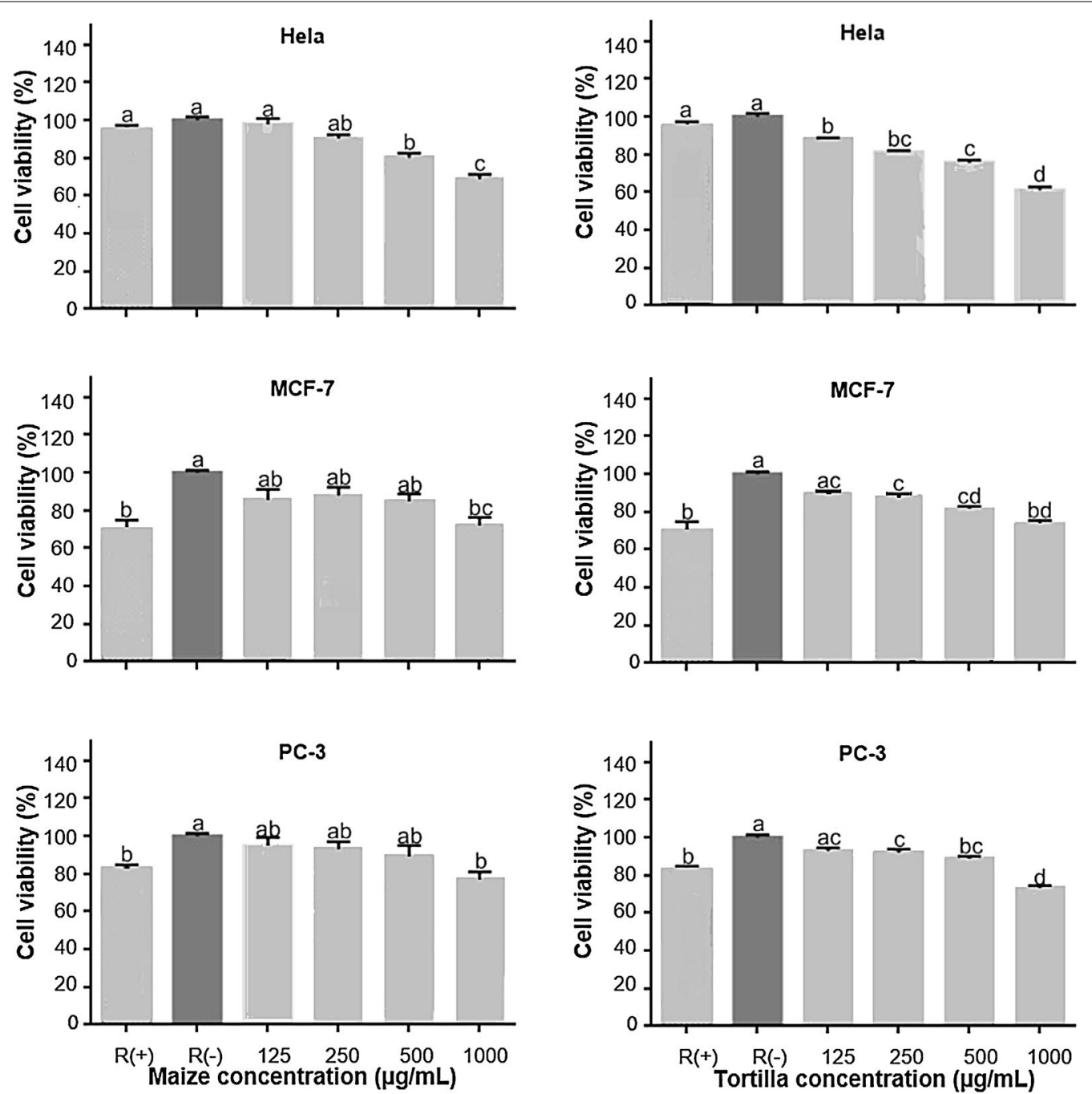

Fig. 3 Effect of blue con and tortilla extracts on cell viability in Hela, MCF-7 and PC-3 human cancer cell lines. R (+). Quercetin $50 \mu M$. R ( - ). Culture medium. Different letters indicate that there are significant differences $(p \leq 0.05)$

Further investigation is required to clarify the molecular mechanism(s) involved in the anticancer activity observed in blue corn and tortilla from maize of the Mixteco race.

\section{Authors' contributions}

$\mathrm{MH}, \mathrm{CC}$ and $\mathrm{CC}$ made an important contribution for the acquisition of the data, analysis, drafting to the manuscript. MR and CC made a significant contribution for the acquisition of the data, analysis, drafting to the manuscript. $\mathrm{HG}$ and JC contributed to draft and to revise the manuscript. RO and RG made a significant contribution for the data analysis and manuscript preparation. All authors read and approved the final manuscript.

\section{Author details}

1 UNIDA, Instituto Tecnológico de Veracruz, M.A. de Quevedo 2779, Col. Formando Hogar, 91897 Veracruz, Veracruz, Mexico. ${ }^{2}$ INMEGEN, Periférico Sur No. 4809, Col. Arenal Tepepan, Delegación Tlalpan, C.P. 14610 Ciudad de Mexico, Mexico. ${ }^{3}$ Instituto de Ciencias Básicas, Universidad Veracruzana, Av. Dr. Luis Castelazo Ayala s/n Col. Industrial Ánimas, 91190 Xalapa, Veracruz, Mexico. ${ }^{4}$ Centro Interdisciplinario de Investigación para el Desarrollo Integral Regional del Instituto Politécnico Nacional-Unidad Oaxaca, Calle Hornos No. 1003, 71230 Santa Cruz Xoxocotlán, Oaxaca, Mexico.

\section{Acknowledgements}

The authors would like to thank the SINAREFI (BEI-MAI-10-33) from México.

\section{Competing interests}

The authors declare that they have no competing interests.

\section{Funding}

The authors have received a funding by National Polytechnic Institute from México for this study.

\section{Publisher's Note}

Springer Nature remains neutral with regard to jurisdictional claims in published maps and institutional affiliations.

Received: 23 September 2016 Accepted: 23 October 2017

Published online: 30 October 2017 


\section{References}

1. Cassidy E, Mukamal KJ, Liu L, Franz M, Eliassen AE, Rimm E (2017) High anthocyanin intake is associated with a reduced risk of myocardial infarction in young and middle-aged women. Circulation 127:188-196

2. Delgado-Vargas F, Paredes-López O (2002) Anthocyanins and betalains. In: Natural colorants for food and nutraceutical uses. CRC, Boca Ratón, pp 167-191

3. Abdel-Aal ESM (2011) Anthocyanin-pigmented grain products. In: Awika JM, Piironen V, Bean S (eds) Advances in cereal science: implications to food processing and health promotion. ACS, Washington, pp 77-109

4. Kato T, Mapes C, Mera L, Serratos J, Bye R (2009) Origen y diversificación del maíz: una revisión analítica. Universidad Nacional Autónoma de México, Mexico

5. FAO (2016) Food and Agriculture Organization. http://faostat.fao.org

6. López-Martinez LX, Parkin KL, Garcia HS (2014) Antioxidant and quinone reductase inducing activities of ethanolic fractions from purple maize. LWT-Food Sci Technol 59:270-275

7. Salinas-Moreno Y, Pérez-Alonso JJ, Vázquez-Carrillo G, Aragón-Cuevas F, Velázquez-Cardelas GA (2012) Antocianinas y actividad antioxidante en maíces (Zea mays L.) de las razas chalqueño, elotes cónicos y bolita. Agrociencia 46:693-706

8. Wang LS, Stoner GD (2008) Anthocyanins and their role in cancer prevention. Cancer Lett 269:281-290

9. Kong JM, Chiam SL, Goh NK, Chia TF, Brouillar C (2003) Analysis and biological activities of anthocyanins. Phytochemistry 64:923-933

10. FAO (1992) Maize in human nutrition. FAO food and nutrition series

11. De la Parra C, Serna-Saldivar SO, Liu RH (2007) Effect of processing on the phytochemical profiles and antioxidant activity of corn for production of masa, tortillas, and tortilla chips. J Agric Food Chem 55:4177-4183

12. Cortes GA, Salinas MY, Martín-Martínez SE, Martínez-Bustos F (2006) Stability of anthocyanins of blue maize (Zea mays L.) after nixtamalization of separated pericarp-germ tip cap and endosperm fractions. J Cereal Sci 43:57-62

13. Singleton VL, Rossi JA (1965) Colorimetry of total phenolics with phosphomolybdic phosphotungstic acid reagents. Am J Enol Vitic 16:144-158

14. Giusti M, Wrolstad RE (2001) Characterization and measurement of anthocyanins by UV visible spectroscopy. In: Giusti MM, Wrolstad RE (eds) Current protocols in food analytical chemistry. Wiley, New York, pp F1.2.1-F1.2.13

15. Brand-Williams W, Cuvelier ME, Berset C (1995) Use of a free radical method to evaluate antioxidant activity. LWT-Food Sci Technol 28:25-30

16. Ohkawa H, Ohishi N, Yagi K (1979) Assay for lipid peroxides in animal tissues by thiobarbituric acid reaction. Anal Biochem 95:351-358

17. Welch CR, Wu Q, Simon JE (2008) Recent advances in anthocyanins analysis and characterization. Curr Anal Chem 4:75-101
18. Mosmann T (1983) Rapid colorimetric assay for cellular growth and survival: application to proliferation and cytotoxicity assays. J Immunol Methods 65:55-63

19. Salinas-Moreno Y, Martinez-Bustos F, Soto-Hernandez M, Ortega-Paczka R, Arellano-Vazquez JL (2003) Effect of alkaline cooking process on anthocyanins in pigmented maize grain. Agrociencia 37:617-628

20. Lao F, Giusti MM (2016) Quantification of purple corn (Zea mays L.) anthocyanins using spectrophotometric and HPLC approaches: method comparison and correlation. Food Anal Methods 9:1367-1380

21. Brownmiller C, Howard LR, Prior RL (2008) Processing and storage effects on monomeric anthocyanins, percent polymeric color, and antioxidant capacity of processed blueberry products. J Food Sci 73:72-79

22. Guzmán-Gerónimo Rl, Alarcón-Aparicio E, García-Barrradas O, AlarcónZavaleta T, Chávez-Servia JL, Alarcón-Zavaleta Tania (2017) Cytotoxic activity of blue corn extract on several cancer cell lines. In: Badria FA (ed) Phytochemistry natural products and cancer. Intech, Rijeka, pp 67-78

23. Nicoué EE, Savard S, Belkacemi K (2007) Anthocyanins in wild blueberries of quebec: extraction and identification. J Agric Food Chem 55:5626-5635

24. Hosseini S, Gharachorloo M, Ghiassi-Tarzi B, Ghavami M (2016) Evaluation of the organic acids ability for extraction of anthocyanins and phenolic compounds from different sources and their degradation kinetics during cold storage. Pol J Food Nutr Sci 66:261-269

25. Dao LT, Takeoka GR, Edwards RH, Berrios JDJ (1998) Improved method for the stabilization of anthocyanidins. J Agric Food Chem 46:3564-3569

26. Gu L (2012) Analysis methods of proanthocyanidins. In: Xu Z, Howard LR (eds) Analysis of antioxidant-rich phytochemicals. Wiley, Oxford, pp 149-180

27. SS (2016) Secretaría de salud de México. http://www.dgis.salud.gob.mx/ contenidos/sinais/e_mortalidadgeneral.htm

28. Bagchi D, Garg A, Krohn RL, Bagchi M, Tran MX, Stohs SJ (1997) Oxygen free radical scavenging abilities of vitamins $C$ and $E$, and a grape seed proanthocyanidin extract in vitro. Res Commun Mol Pathol Pharmacol 95:179-189

29. Weaver J, Briscoe T, Hou M, Goodman C, Kata S, Ross H, McDougall G, Stewart D, Riches A (2009) Strawberry polyphenols are equally cytotoxic to tumourigenic and normal human breast and prostate cell lines. Int J Oncol 34:777-786

30. Nandakumar V, Singh T, Katiyar SK (2009) Multi-targeted prevention and therapy of cancer by proanthocyanidins. Cancer Lett 269:378-387

31. Duo J, Ying GG, Wang GW, Zhang L (2012) Quercetin inhibits human breast cancer cell proliferation and induces apoptosis via Bcl-2 and Bax regulation. Mol Med Rep 5:1453-1456

\section{Submit your manuscript to a SpringerOpen ${ }^{\circ}$ journal and benefit from:}

- Convenient online submission

- Rigorous peer review

- Open access: articles freely available online

- High visibility within the field

Retaining the copyright to your article

Submit your next manuscript at springeropen.com 